\title{
The neuropsychology of moderate head injury
}

\author{
T M MCMILLAN,* E E GLUCKSMAN†
}

From the Department of Clinical Psychology, Institute of Psychiatry, ${ }^{*}$ and the Department of Accident and Emergency, $\dagger$ King's College Hospital, London, UK

SUMMARY Twenty four patients were tested on a battery of neuropsychological tests within one week of sustaining a moderate head injury. Their ability to process information rapidly was impaired in comparison with a control group that had sustained orthopaedic injuries. Differences between groups were not found on tests of intelligence and memory. This selective cognitive deficit may be due to brain damage associated with moderate head injury.

For some time there has been controversy over whether post-concussional symptoms are psychogenic or $^{1-3}$ organically based. ${ }^{4-6}$ In recent years there has been growing support for the view that organic damage can result from "minor" (mildmoderate) head injury. Neuropathological evidence has been reported in both animals ${ }^{7-9}$ and in humans. ${ }^{1011}$ Studies in neurophysiology have observed increased blood-brain permeability, ${ }^{12}$ slowing of cerebral circulation, ${ }^{13}$ brainstem impairment, ${ }^{14-17}$ and greater sensitivity to light. ${ }^{18}$ The present study is concerned with the neuropsychology of moderate (PTA 1-24 hours) ${ }^{19}$ head injury. Whereas gross deficits in intelligence or memory have not been reported in "minor" head injury, ${ }^{2021}$ more subtle impairments in the rate of information processing and in reaction time have been found. ${ }^{20-23}$

The study of head injury is fraught with methodological difficulties, ${ }^{24}$ and a number of the above studies could have benefited from improved design. McKinlay and Brooks ${ }^{24}$ stressed the need for an appropriate control group in such studies. Ideally a control group should differ from a head injured group only by not having sustained a brain injury. Hence a comparison group should control for the physical damage, shock, stress and disability arising from the injury. Controls should also belong to a population that has a similar likelihood of sustaining a head injury. ${ }^{24}$ That is to say an over-representation of younger males from lower socio-economic groups would be expected. ${ }^{25}$

Address for reprint requests: Dr TM McMillan, Department of Clinical Psychology, Institute of Psychiatry, De Crespigny Park, London SE5 8AF, UK.

Received 9 May 1986.

Accepted 1 August 1986
Studies on mild or moderate head injury have often failed to incorporate an appropriate control group according to these criteria. ${ }^{14-18}$ Neuropsychological studies have used "normal" subjects for comparison, or heterogeneous patient groups which include different severities of head injury, or have used patients as their own controls in longitudinal investigations. $^{20-23}$ The latter studies also suffer from the absence of information which clearly relates intelligence or memory ability to concentration or reaction time deficits. ${ }^{22}{ }^{23}$ Findings of a poorer rate of information processing in head injured patients could therefore be due to a lower premorbid intelligence or memory than found in a "normal" control group, especially because the head injured group is likely to belong to a different population in terms of "at risk" factors for injury factor. The presence of cognitive deficits following severe head injury is clearly established. ${ }^{43}$ However, some studies which have claimed or been cited as supporting the view that brain damage occurs following mild or moderate head injury are made less convincing by use of groups which are heterogeneous in terms of severity of injury. ${ }^{132627}$

The present study examined the hypothesis that relatively subtle deficits in the rate of information processing ${ }^{11}$ can occur shortly after a moderate head injury in the absence of more gross impairments in intelligence or memory. An experimental method designed to overcome some of the problems identified in previous studies was utilised.

\section{Method}

Procedure All patients were seen within 7 days of sustaining an injury. Where possible patients were interviewed and assessed together with a relative or close friend. Details of the accident were obtained from hospital notes and from the patient. A checklist of post-concussional symptoms was 
completed by both the patient and a relative or close friend. Patients The experimental group consisted of 24 moderately head injured (MHI) patients, who were admitted to casualty and held overnight for observation. This group would normally be included in the category "minor head injury" together with mild and very mild cases. ${ }^{1925}$ It was selected for investigation because of the paucity of studies on MHI and because PTA duration can be difficult to assess reliably if less than one hour. Moderate head injury was defined by a duration of post-traumatic amnesia (PTA) of between 1 and 24 hours. ${ }^{19}{ }^{25}$ All MHI cases had been unconscious as a result of this injury. The control group (OC) consisted of 20 patients who had sustained an orthopaedic injury which usually involved an upper limb fracture or sprain.

Patients who had a psychiatric history or who were outwith the age range of 15-60 years were excluded from the study. Excessive alcohol drinking can mimic PTA and can therefore make estimations of PTA inaccurate in minor head injury cases because the duration of PTA is relatively short. Hence, patients who were intoxicated on admission were excluded from the study. Five patients from the MHI group and one from the OC group had previously sustained a minor head injury (PTA less than 24 hours). In all of these cases the injury took place more than 4 years previously. No patient had any outstanding claims for compensation. All patients were obtained from the Accident and Emergency Department of King's College Hospital, London.

Neuropsychological testing A short version of the WAIS-R was used, including the Vocabulary, Comprehension, Similarities, Block Design and Object Assembly subtests. ${ }^{29}$ These subtests were used to provide an estimate of general intellectual ability as well as a contrast between verbal and spatial intelligence ${ }^{29}$ together with the more traditional estimates of verbal (VIQ) and performance (PID) IQ. ${ }^{28}$

Verbal memory was assessed using the Paired Associate Learning (PALT) and Logical Memory (LM) subtests of the Wechsler Memory Scale. ${ }^{30}$

The Rey-Osterrieth Complex Figure Test (RO) provided an estimate of non-verbal memory. ${ }^{31}$ Delayed recall was tested $\mathbf{4 5}$ minutes after initial presentation for both the LM and RO tests.

The rate of information processing was investigated using the Paced Auditory Serial Addition Test (PASAT) ${ }^{22}$ During this test patients were required to make 60 additions,

Table 1 Moderate head injury (MHI) and orthopaedic control (OC) groups

\begin{tabular}{lcc}
\hline & $M H I$ & $O C$ \\
\hline Number (male) & $24(16)$ & $20(11)$ \\
Age & $31 \cdot 2 \pm 12 \cdot 0$ & $34 \cdot 8 \pm 14 \cdot 7$ \\
Cause of injury (\%) & $10(42)$ & $1(5)$ \\
RTA & $9(34)$ & $1(5)$ \\
Assault & $4(17)$ & $12(60)$ \\
Fall & $1(4)$ & $6(30)$ \\
Other & 3 & 5 \\
Social class: & 10 & 8 \\
I and II & 7 & 7 \\
III & 9 & 6 \\
IV and V & & \\
Unemployed & & \\
\hline
\end{tabular}

each of two, single digit numbers. These numbers were presented serially by tape recorder. Initially the patient was allowed to practice, and the numbers were then presented at the "slow" rate (one number every 4 seconds). In a second trial the numbers were repeated at the "fast" rate (one number every 2 seconds). The number of correct responses were scored for each trial. Patients who repeatedly performed poorly during the practice trial or on the "slow" trial were suspected of having poor basic numeracy and were excluded from the study.

Both patients and relatives completed the Subjective Memory Questionnaire (SMQ), ${ }^{32}$ a self-report of everyday memory ability which has previously been found to distinguish between normal and brain injured groups. ${ }^{34} 35$

\section{Results}

Patient variables (table 1) Differences between MHI and $\mathrm{OC}$ groups were non-significant for age $(t=0.90$, $\mathrm{p}>0.05$ ), sex (chi squared $=0.23, \mathrm{p}>0.05$ ) or employment (chi squared $=0.23, p>0.05$ ). For the purposes of analysis, social class was compared between groups I + II, III, IV + V; differences in distribution of class were non-significant between groups (chi squared $=3.6, p>0.05$ ). Some patients had been drinking alcohol prior to the accident but were not intoxicated on admission; the frequency of occurrence of such cases did not differ significantly between groups (chi squared $=2 \cdot 7, p>0.05$ ).

Injury (table 1) was more frequently caused by a road traffic accident (RTA), or an assault in the MHI group and with a fall in the $\mathrm{OC}$ group (chi squared $=0$ $21 \cdot 1, \mathrm{p}<0.0001)$.

Clinical variables All MHI patients were unconscious for less than 15 minutes. On admission the score on the Glasgow Coma Scale ${ }^{25}$ was 464 in five MHI cases (confused conversation) and 465 (normal) in all other cases. Skull fracture was not evident in any patient, and none had pre- or post-traumatic epilepsy.

During admission $55 \%\left({ }^{12} / 22\right)$ of $\mathrm{MHI}$ and $32 \%(6 / 19)$ of control patients were given analgesic drugs. The differences in the frequency of drug prescription were non-significant (chi squared $=1.35$, p $>0.05$ ). The majority of prescriptions were for aspirin or paracetamol $(n=8)$ or a codeine-like drug $(n$ $=8$ ). A single dose of pethidine or similar was given acutely and in only two cases, one of which belonged to the MHI group.

Post-concussional symptoms Table 2 indicates differences in the self-reporting of post-concussional symptoms by patients. Relatives were given a more elaborate 16-item checklist which incorporated a sixpoint rating scale of severity. The MHI patients were more often reported by relatives as being quieter (chi squared $=7.96, \mathrm{p}<0.01$ ) and more tense (chi squared $=4.63, \mathrm{p}<0.01$ ) than OC patients. Relatives in $\mathrm{MHI}$ and $\mathrm{OC}$ groups did not report a different 
frequency or severity of other symptoms. These included patients being irritable, worried, impatient, angry, violent, childlike, forgetful, depressed, happy, calm, peaceful, relaxed or "at ease" ( $p>0.05)$.

Neuropsychological tests Table 3 clearly shows that differences in objective tests of intelligence and memory were all non-significant $(p>0.05)$. The range of general IQ in the MHI group (74-114) was similar to that in the OC group (70-123). Moderate head injury patients performed less well on the "fast" (one word per 2 second) administration of the PASAT $(p<0.01)$, but differences were not found between groups at the "slow" (one per 4 second) rate $(\mathrm{p}>0.05$ ). This would support the view that there were deficits in the rate of information processing in the head injured patients. ${ }^{18}$ Scores for the PASAT did not correlate with general IQ in either group $(\mathrm{p}>$ 0.05 ). Ratings of everyday memory ability from the SMQ were lower in MHI than in OC patients ( $p<$ $0.04)$. Differences for relatives' ratings were nonsignificant between groups ( $p>0 \cdot 05)$.

It could be argued that group differences in the scores for the PASAT at the "fast" rate are in part due to the somewhat higher proportion of patients with a history of head injury in the MHI group, even though these injuries were minor and occurred more than 4 years prior to testing. Neuropsychological test results were therefore re-analysed with cases of previous head injury omitted. Differences between MHI $(n=17)$ and $O C(n=17)$ groups remained extremely similar. Patients in the MHI group again scored more poorly on the "fast" trial of PASAT $(t=2 \cdot 24$,

Table 2 Post-concussional symptoms reported by $M H I$ and $O C$ patients (percent of group)

\begin{tabular}{llccc}
\hline Symptom & MHI (\%) & OC (\%) & Chi squared \\
\hline Headache & 71 & 10 & $14 \cdot 1$ & Probability \\
Dizziness & 46 & 5 & $7 \cdot 2$ & $<0 \cdot 001$ \\
Irritability & 64 & 16 & $7 \cdot 8$ & $<\cdot 01$ \\
Fatigue & 75 & 25 & 0.005 & $<0.005$ \\
Intolerance to noise & 38 & 0 & $7 \cdot 3$ & $<.01$ \\
Intolerance to bright lights & 33 & 0 & $6 \cdot 1$ & 0.02 \\
\hline
\end{tabular}

Table 3 Scores on neuropsychological tests for moderate head injury (MHI) and orthopaedic control (OC) groups

\begin{tabular}{|c|c|c|c|c|c|c|}
\hline Cognitive function & Group & $N$ & Mean & $S D$ & $d f$ & $t$ \\
\hline \multicolumn{7}{|l|}{ Intelligence: } \\
\hline Verbal & $\begin{array}{l}\text { MHI } \\
\text { OC }\end{array}$ & $\begin{array}{l}24 \\
20\end{array}$ & $\begin{array}{r}96 \cdot 5 \\
102 \cdot 1\end{array}$ & $\begin{array}{l}12 \cdot 2 \\
18 \cdot 6\end{array}$ & 42 & 1.21 \\
\hline Performance & $\begin{array}{l}\text { MHI } \\
\text { OC }\end{array}$ & $\begin{array}{l}22 \\
10\end{array}$ & $\begin{array}{l}96.0 \\
98.0\end{array}$ & $\begin{array}{l}14 \cdot 6 \\
16 \cdot 5\end{array}$ & 40 & 0.42 \\
\hline General & MHI & 22 & 94.9 & $12 \cdot 3$ & 40 & 0.33 \\
\hline & OC & 20 & $96 \cdot 3$ & $14 \cdot 7$ & & \\
\hline Spatial contrast & MHI & 22 & 99.0 & 11.9 & 40 & 0.68 \\
\hline Verbal memory: & $\mathrm{OC}$ & 20 & $96 \cdot 3$ & $14 \cdot 8$ & & \\
\hline $\begin{array}{l}\text { Verbal memory: } \\
\text { Paired associates }\end{array}$ & $\begin{array}{l}\text { MHI } \\
\text { OC }\end{array}$ & $\begin{array}{l}24 \\
20\end{array}$ & $\begin{array}{l}14 \cdot 7 \\
15 \cdot 4\end{array}$ & $\begin{array}{l}5 \cdot 2 \\
3 \cdot 2\end{array}$ & 42 & 0.45 \\
\hline Logical memory (IR) & $\mathrm{MHI}$ & 24 & $10 \cdot 4$ & 3.0 & 42 & 0.95 \\
\hline Logical memory (DR) & $\begin{array}{l}\mathrm{OC} \\
\mathrm{MHI}\end{array}$ & $\begin{array}{l}20 \\
23\end{array}$ & $\begin{array}{r}11.4 \\
9.1\end{array}$ & $3 \cdot 5$ & $A 1$ & $0 \cdot 22$ \\
\hline Logical memory (DK) & OC & $\begin{array}{l}23 \\
20\end{array}$ & $9 \cdot 1$ & $\begin{array}{l}3.4 \\
3 \cdot 1\end{array}$ & 41 & 0.22 \\
\hline Logical memory (PR) & $\begin{array}{l}\text { MHI } \\
\text { OC }\end{array}$ & 23 & $\begin{array}{l}86 \cdot 2 \\
82 \cdot 7\end{array}$ & $\begin{array}{l}24.9 \\
12 \cdot 8\end{array}$ & 41 & 0.56 \\
\hline \\
\hline Rey (DR) & $\begin{array}{l}\text { MHI } \\
\text { OC }\end{array}$ & $\begin{array}{l}21 \\
18\end{array}$ & $\begin{array}{l}24 \cdot 1 \\
23 \cdot 3\end{array}$ & $\begin{array}{l}6 \cdot 2 \\
7 \cdot 6\end{array}$ & 37 & $0 \cdot 37$ \\
\hline Rey (PR) & MHI & 21 & $68 \cdot 1$ & $16 \cdot 2$ & 37 & $0 \cdot 25$ \\
\hline & $69 \cdot 6$ & $19 \cdot 0$ & & \\
\hline $\begin{array}{l}\text { Attention (PASA I): } \\
\text { Slow }\end{array}$ & $\begin{array}{l}\text { MHI } \\
\text { OC }\end{array}$ & $\begin{array}{l}24 \\
20\end{array}$ & $\begin{array}{l}49 \cdot 2 \\
51 \cdot 3\end{array}$ & $\begin{array}{r}10 \cdot 1 \\
7 \cdot 1\end{array}$ & 42 & 0.80 \\
\hline Fast & MHI & 24 & 25.9 & $10 \cdot 4$ & 42 & $2 \cdot 80^{*}$ \\
\hline & & 20 & $34 \cdot 6$ & 9.9 & & \\
\hline SMQ (patient's report) & MHI & 23 & $136 \cdot 8$ & $18 \cdot 0$ & 41 & $2 \cdot 20 \dagger$ \\
\hline SMQ (relative's report) & $\begin{array}{l}\mathrm{OC} \\
\mathrm{MHI}\end{array}$ & $\begin{array}{l}20 \\
16\end{array}$ & $\begin{array}{l}148 \cdot 6 \\
151.8\end{array}$ & $\begin{array}{l}16 \cdot 8 \\
15 \cdot 2\end{array}$ & 28 & 0.93 \\
\hline Sive (Itative sicporit) & $\mathrm{OC}$ & 14 & $145 \cdot 8$ & 19.8 & & \\
\hline
\end{tabular}

$* \mathrm{p}<0.01 ;$ tp $<0.05$. 
$p<0.03$ ). Self-ratings of memory continued to be lower in reports by MHI patients $(t=2 \cdot 13, \mathrm{p}<0.05)$. Differences between groups remained non-significant for all other tests $(p>0.05)$.

Possible effects of analgesic drugs on test performance were explored by comparing test results of drug and drug-free cases. Differences between groups were non-significant for all neuropsychological tests $t$ test $(\mathrm{p}>0.05)$. Analysis of variance did not reveal any significant interactions between drug and patient groups for any test $(p>0.05)$.

\section{Discussion}

The prediction that rate of information processing is impaired following a moderate head injury was supported by results from the "fast" trial of the PASAT. Both groups performed equally and well on the "slow" trial obtaining more than $80 \%$ correct answers. The "slow" trial (4 minutes) lasts twice as long as the "fast" ( 2 minutes) trial (see procedure). Group differences cannot therefore be simply explained by an overall deficit in sustained attention in the MHI group. Degree of task difficulty would seem to be important and results would be consistent with the view that the rate of information processing (rather than the ability to process such information) is reduced.

Impairment in the MHI group is clearly evident, but whether this can be attributed to brain damage remains dependent on the adequacy of the control group. The OC cases were similar to the MHI group in terms of "at risk" factors for injury. ${ }^{24}$ These factors included age, sex, social class and employment status. Intelligence and memory ability were also similar between groups and importantly, deficits in the rate of information processing could not be attributed to a poorer level of general cognitive functioning in the MHI group. Claims for compensation following injury have been associated with post-concussional neuroses, ${ }^{12}$ although more recent evidence would suggest that this case has been over-stated. ${ }^{36}{ }^{37}$ In the present study, compensation claims were not an issue as none were planned or outstanding at the time of testing. Repeated concussion has been reported to have cumulative effects on cognitive functioning ${ }^{38}$ and some patients in this study had previously sustained head injuries. However, the finding that a selective cognitive deficit in the rate of information processing persists when cases with a history of prior head injury were excluded from analysis suggests that this is not a significant variable in this study. Finally, the inclusion only of patients who had sustained a moderate head injury avoids difficulties in interpretation found elsewhere when patient groups are heterogeneous in terms of the severity of head injury.
The close similarity between MHI and OC groups implies that differences in performance on the "fast" rate of the PASAT are due to differences in the nature of the injury between these groups. At least two possible causes of impaired PASAT performance in MHI patients remain. First, the effect is caused by brain damage. Second, there is greater stress associated with head injury than with orthopaedic injury in this study. The latter interpretation might gain support if more stress is associated with a road traffic accident or an assault than with a fall. If this was the case here, then the deficit in information processing in the MHI group would be due to accident associated stress rather than brain injury. The low frequencies of RTA and assault in OC cases makes further analysis of this problem difficult in the present study. The weight of evidence might however favour an interpretation in terms of brain injury. If accident associated stress was significantly greater in the MHI group, more frequent requests for and prescriptions of analgesic drugs might have been expected, but were not found. In addition an organic interpretation would be supported by evidence from previously cited neuropsychological and neuropathological studies.

Whichever is the source of the deficit, implications for the care of moderate head injured patients remain. It is evident that within a few days of injury, MHळ patients not only have impairments in the ability to process information rapidly, but subjectively repop post-concussional symptoms. These include head $\vec{\omega}$ aches, dizziness, fatigue, irritability, sensitivity to noise and bright lights and poorer memory for everyday items and events. Relatives did not report these effects, but did detect other post-injury changes and stated that MHI patients were more quiet and tense. Soon after injury there is therefore disparity between the perceptions of patients and their relatives regarding psychological sequelae of the accident. This could indicate a basis for the development of psychosocial problems in some cases (such as marital difficulties), as has been reported for severe head injury cases. ${ }^{3940}$ Difficulty in concentrating could in addition affect work performance, and more generally these patients might be more susceptible to everyday stress. The potential for the development of these problems in "minor" head injury patients has been pointed out by other authors. ${ }^{36}{ }^{4142}$ It is especially pertinent because these patients often receive little or no advice or follow-up after discharge. The role of counselling and follow-up in these patients with a view towards the prevention of the development of such problems is worthy of further investigation.

\section{References}

1 Miller H. Accident neurosis. Br Med J 1961;i:919-25, 992-8. 
2 Miller H. Mental sequelae of head injury. Proc $R$ Soc Med 1966;59:257-61.

3 Lidvall HF, Linderoth B, Norlin B. Causes of the post concussional syndrome. Acta Neurol Scand Supp 56, 1974;50.

4 Symonds C. Concussion and its sequelae. Lancet 1962;1:1-5.

5 Russell WR. Recovery after minor head injury. Lancet 1974;2:1315.

6 Taylor AR. Post-concussional sequelae. $B$ Med J 1967;3:67-71.

7 Ommaya AK, Gennarelli TA. Cerebral concussion and traumatic unconsciousness. Brain 1974;97:633-54.

8 Jane JA, Rimel RW, Pobereskin LH, Tyson GW, Stewart O, Gennarelli TA. Outcome and pathology of head injury. In: Granman RG, Gildenburg PL, eds. Head Injury: Basic and Clinical Aspects. New York: Raven Press, 1982.

9 Povlishock JT, Becker DP, Cheng CLY, Vaughn GW. Axonal change in minor head injury. $J$ Neuropathol Clin Neurol 1983;42:225-42.

10 Oppenheimer DR. Microscopic lesions in the brain following head injury. J Neurol Neurosurg Psychiatry 1968;31:299-306.

11 Clarke JM. Distribution of microglial scars in the brain after head injury. $J$ Neurol Neurosurg Psychiatry 1974;34:463-74.

12 Zetterholm S. Blood-spinal permeability to bromide in closed head injuries. Acta Psychiatrica Neurol Scand Suppl XLV 1947.

13 Taylor AR, Bell TK. Slowing of cerebral circulation after concussional head injury. Lancet 1966;ii:178-80.

14 Rowe MJ, Carlson C. Brainstem auditory evoked potentials in post-concussion dizziness. Arch Neurol 1980;37:679-83.

15 Noseworthy JH, Miller J, Murray TJ, Regan D. Auditory brainstem responses in post concussion syndrome. Arch Neurol 1981;38:275-8.

16 Montgomery A, Fenton GW, McLelland RJ. Delayed brainstem conduction time in post-concussional syndrome. Lancet 1984;1:1011.

17 McLelland RJ. A neurophysiological investigation of minor head injury. In: Papakostopoulos D, Butler S, Martin I, eds. Clinical and Experimental Neurophysiology. London: Croom Helm, 1985.

18 Waddell PA, Gronwall DMA. Sensitivity to light and sound following minor head injury. Acta Neurol Scand 1984;69:270-6.

19 Russell WR. Post traumatic amnesia in closed head injury. Arch Neurol 1961;5:16-29.

20 Gronwall D, Wrightson P. Memory and information processing capacity after minor head injury. $J$ Neurol Neurosurg Psychiatry 1981;44:889-95.

21 Rimel RW, Giordani B, Barth JT, Ball JT, Jane JA. Disability caused by minor head injury. Neurosurgery 1981;9:221-8.

22 Gronwall D, Wrightson P. Delayed recovery of intellectual function after minor head injury. Lancet 1974;2:605-9.

23 MacFlynn G, Montgomery EA, Fenton GW, Rutherford W. Measurement of reaction time following minor head injury. $J$ Neurol Neurosurg Psychiatry 1984;47:1326-31.

24 McKinlay WW, Brooks DN. Methodological problems arising in assessing psychosocial recovery following severe head injury. J Clin Neuropsychol 1984;6:87-99.

25 Jennett B, Teasdale G. Management of Head Injuries. Philadelphia: Davis and Co, 1981.

26 Brouwer WH, Van Wolffelaar PC. Sustained attention and sustained effort after closed head injury: detection and $0 \cdot 10 \mathrm{~Hz}$ heart rate variability in a low event rate vigilance task. Cortex 1985;21:111-9.

27 Dikman S, Reitan RM, Temkin NR. Neuropsychological recovery in head injury. Arch Neurol 1983;40:333-8.

28 Wechsler D. Wechsler Adult Intelligence Scale Revised. New York: The Psychological Corporation, 1981.

29 Canavan AGM, Dunn G, McMillan TM. Principal components analysis of the WAIS-R. Br J Clin Psychol 1986;25:81-85.

30 Wechsler D. A standardised memory scale for clinical use. J Neurol Neurosurg Psychiatry 1954;15:54-8.

31 Lezak M. Neuropsychological Assessment. Oxford: Oxford University Press, 1983.

32 Bennett-Levy J, Powell GE. The subjective memory questionnaire (SMQ) and investigation into the selfreporting of "real life" memory skills. Br J Clin Psychol 1980;19:177-88.

33 McMillan TM. Investigation of everyday memory in normal subjects using the subjective memory questionnaire (SMQ). Cortex 1984;20:333-47.

34 Bennett-Levy J, Polkey CE, Powell GE. Self-report of memory skills after temporal lobectomy: the effect of clinical variables. Cortex 1980;16:543-57.

35 McMillan TM. Investigation of everyday memory in normal and head injured subjects using the Subjective Memory Questionnaire. M App Sci Thesis. University of Glasgow, 1983.

36 Kelly R, Smith BN. Post-traumatic syndrome: another myth discredited. J R Soc Med 1981;74:275-7.

37 McKinlay WW, Brooks DN, Bond MR. Postconcussional symptoms, financial compensation and outcome of severe head injury. $J$ Neurol Neurosurg Psychiatry 1983;46:1084-91.

38 Gronwall D, Wrightson P. Cumulative effects of concussion. Lancet 1975;ii:995-7.

39 Brooks DN. Head injury and the family. In: Brooks DN, ed. Closed Head Injury. Oxford: Oxford University Press, 1983.

40 Livingston MG, Brooks DN, Bond MR. Patient outcome in the year following severe head injury and relatives psychiatric and social functioning. J Neurol Neurosurg Psychiatry 1985;48:876-81.

41 Relander M, Trapp H, Bjorkesten G. Controlled trial of treatment for cerebral concussion. Br Med $J$ 1972;4:777-9.

42 Gronwall DMA. Paced auditory serial-addition task: a measure of recovery from concussion. Percept Mot Skills 1977;44:367-73.

43 Brooks DN. Cognitive deficits after head injury. In: Brooks DN, ed. Closed Head Injury. Oxford: Oxford University Press, 1983. 